\title{
Energy Cost of Children's Structured and Unstructured Games
}

\author{
Kimberly A. Clevenger, Aubrey J. Aubrey, Rebecca W. Moore, \\ Karissa L. Peyer, Darijan Suton, Stewart G. Trost, and Karin A. Pfeiffer
}

\begin{abstract}
Background: Limited data are available on energy cost of common children's games using measured oxygen consumption. Methods: Children (10.6 \pm 2.9 years; $\mathrm{N}=37 ; 26$ male, 9 female) performed a selection of structured (bowling, juggling, obstacle course, relays, active kickball) and unstructured (basketball, catch, tennis, clothespin tag, soccer) activities for 5 to 30 minutes. Resting metabolic rate (RMR) was calculated using Schofield's age- and sex-specific equation. Children wore a portable metabolic unit, which measured expired gases to obtain oxygen consumption $\left(\mathrm{VO}_{2}\right)$, youth METs (relative $\mathrm{VO}_{2} / \mathrm{child}^{\prime} \mathrm{s}$ calculated RMR), and activity energy expenditure ( $\mathrm{kcal} / \mathrm{kg} / \mathrm{min})$. Descriptive statistics were used to summarize data. Results: Relative $\mathrm{VO}_{2}$ ranged from $16.8 \pm 4.6 \mathrm{ml} / \mathrm{kg} / \mathrm{min}$ (bowling) to $32.2 \pm 6.8 \mathrm{ml} / \mathrm{kg} / \mathrm{min}$ (obstacle course). Obstacle course, relays, active kickball, soccer, and clothespin tag elicited vigorous intensity ( $>6 \mathrm{METs}$ ), the remainder elicited moderate intensity (3-6 METs). Conclusions: This article contributes energy expenditure data for the update and expansion of the youth compendium.
\end{abstract}

Keywords: physical activity, adolescent, measurement

In the Compendium of Energy Expenditures for Youth developed by Ridley et al, ${ }^{1} 35 \%$ of MET values were based on data measured in youth. The remaining activities were deemed those in which children participate, but MET values were based on adult data. Children expend more energy relative to body weight than adults at rest or when performing the same activity, and energy expenditure at rest or during an activity decreases with age.,3 This has been attributed to immature motor patterns, physiological factors (eg, increased respiratory rate, reliance on aerobic metabolism), and the fact that children often put forth more effort to perform a task due to their smaller body size and lesser strength. ${ }^{2,4}$ As such, research demonstrated that overall, adult METs slightly underestimated child METs as determined by measured oxygen consumption, but the amount of under- or over-estimation differed by activity. ${ }^{2}$ These differences may be further exaggerated during locomotive activities due to children's inefficient gait patterns. ${ }^{2}$

For valid estimates of intensity, energy expenditure of activities that are common to children should be measured in children. ${ }^{5}$ Activities common during recess or physical education class are of importance because they can be recommended to promote moderateto-vigorous activity. ${ }^{5}$ However, limited energy expenditure data are available for these activities. ${ }^{5}$ The purpose of this study was to assess the energy cost of common children's games using measured oxygen consumption.

\section{Methods}

Children, aged 5 to 15 years, with no conditions that affected participation in physical activity or measurement of metabolic

Clevenger (cleven18@msu.edu), Aubrey, Suton, and Pfeiffer are with the Dept of Kinesiology, Michigan State University. Moore is with the School of Health Promotion and Human Performance, Eastern Michigan University. Peyer is with the Dept of Kinesiology, Iowa State University. Trost is with the Center for Children's Health Research, Queensland University of Technology. data, were recruited through faculty and parent e-mail lists to participate in this study. Before participation, children and parents completed informed assent and consent forms, respectively. The Institutional Review Board at Michigan State University approved this study.

Children were asked to abstain from caffeine, food, and beverages (besides water) for 2 hours before their visit. Height was measured to the nearest $0.1 \mathrm{~cm}$ by a wall-mounted stadiometer (Harpenden). Weight was measured to the nearest $0.1 \mathrm{~kg}$ by a digital scale (Seca 770, Hanover, Maryland). Resting Metabolic Rate (RMR) was calculated using the age- and sex-appropriate Schofield equation using height and weight. ${ }^{6}$

This investigation was part of a study that aimed to simulate an afterschool program, so the participants had other children with whom to play. The visit began with structured play, then "homework" (no data), and ended with unstructured play. The structured play was either a "low-intensity" session including bowling and scarf juggling or a "high-intensity" session including obstacle course, relays, and active kickball. Structured games were played for 8 to 10 minutes each. During unstructured play, children could choose from the following games: catch, basketball, tennis, clothespin tag, or soccer. Overall time for unstructured play was 20 to 30 minutes, but time for individual games was not regulated. Start and stop times were determined from video. Descriptions of activities are found in Table 1.

During play, children wore the Oxycon Mobile portable metabolic unit (Carefusion, Yorba Linda, CA), which measured breathby-breath oxygen consumption. The metabolic unit was calibrated with standard gases before each subject's visit. To remove time for instructions and represent typical game play, the first 2 minutes and last minute of each game's data were removed from analysis. Game play shorter than 2 minutes in duration after removal of the previously described 3 minutes was not used for analysis. Any oxygen consumption data below calculated RMR or more than 3 standard deviations above the activity's mean oxygen consumption were deemed outliers and removed. Youth METs were calculated as oxygen consumption $(\mathrm{ml} / \mathrm{kg} / \mathrm{min})$ divided by child's calculated 
Table 1 Description of Study Activities

\begin{tabular}{ll}
\hline Activity & Description \\
\hline $\begin{array}{l}\text { Bowling } \\
\text { Juggling }\end{array}$ & $\begin{array}{l}\text { Indoor bowling with plastic pins and plastic ball in gym } \\
\text { Juggling with light-weight, colorful scarves } \\
\text { Catching using a Velcro mitt and tennis ball } \\
\text { Obstacle Course }\end{array}$ \\
Relays & $\begin{array}{l}\text { Performing hula hoop, push-ups, squats, bean bag toss, etc. } \\
\text { Moving between cones while translocating across a gym, performing activities such as shuttle runs, high knees, or } \\
\text { walking "like a duck" }\end{array}$ \\
Active Kickball & $\begin{array}{l}\text { Similar to traditional kickball, but children continued moving while on base by doing jumping jacks, hopping on 1 foot, } \\
\text { dancing, or marching in place }\end{array}$ \\
Basketball & Unstructured basketball indoors, ratio of children playing to number of balls was variable, full game or shooting hoops \\
Tennis & Unstructured indoor tennis without a net, using plastic rackets and foam ball or regular tennis ball \\
Clothespin tag & $\begin{array}{l}\text { Tag in a confined area wherein children aim to collect the most clothespins by removing them from other children's shirts } \\
\text { (while protecting their own) }\end{array}$ \\
Soccer & Unstructured soccer using regular ball and medium-sized nets on half of a gym floor \\
\hline
\end{tabular}

RMR ( $\mathrm{ml} / \mathrm{kg} / \mathrm{min})$. Moderate intensity was defined as 3-6 Youth METs, while vigorous was defined as $>6$ METs. $^{7}$ Energy expenditure $(\mathrm{kcal} / \mathrm{kg} / \mathrm{min})$ was calculated by multiplying absolute $\mathrm{VO}_{2}(\mathrm{~L} /$ $\min$ ) by the conversion factor $4.86 \mathrm{kcal} / \mathrm{L} \mathrm{O}_{2}$, subtracting calculated RMR ( $\mathrm{kcal} / \mathrm{min})$, and dividing by weight $(\mathrm{kg}) .{ }^{8}$ Descriptive statistics were used to summarize data.

\section{Results}

Subjects were 26 male and 9 female youth aged $10.6 \pm 2.9$ years. Eight subjects were overweight or obese (Body Mass Index $\geq 85$ th percentile). Three girls and 9 boys were 10 years or younger, while 6 girls and 17 boys were over the age of 10 years. Subjects were $147.6 \pm 17.2 \mathrm{~cm}$ in height, and $68.2 \pm 12.4 \mathrm{~kg}$ in weight. Energy expenditure and youth MET levels are outlined in Table 2. Bowling, juggling, catch, basketball, and tennis elicited moderate intensity activity (3-6 METs). Obstacle course, relays, active kickball, soccer, and clothespin tag elicited vigorous intensity activity (>6 METs). Bowling elicited the lowest MET level (3.6 \pm 0.9$)$, while obstacle course, relays, and clothespin tag elicited the highest MET levels $(7.1 \pm 1.4,7.1 \pm 1.5$, and $7.1 \pm 1.0$, respectively $)$

Although no statistical analysis was completed due to sample size, boys elicited greater METs during bowling (3.8 \pm 0.8 vs. 2.7 $\pm 1.0)$, juggling $(4.4 \pm 1.1$ vs. $3.2 \pm 0.7)$, basketball $(6.0 \pm 1.7$ vs. $5.0 \pm 0.8)$, tennis $(4.6 \pm 0.7$ vs. $3.8 \pm 1.1)$, clothespin tag $(7.3 \pm$ 1.1 vs. $6.7 \pm 0.5)$, and catch $(4.1 \pm 0.7$ vs. $3.2 \pm 0.7)$ than girls, but similar METs during obstacle course (7.1 \pm 1.4 vs. $7.2 \pm 1.4)$. Boys elicited lower MET levels during relays $(6.8 \pm 1.5$ vs. $7.7 \pm 1.4)$, active kickball $(6.4 \pm 1.4$ vs. $7.5 \pm 1.0)$, and soccer $(6.4 \pm 1.8$ vs. $7.1 \pm 1.1)$ than girls.

\section{Discussion}

This study aimed to determine the energy expenditure of several common children's games. Obstacle course, relays, active kickball, soccer, and clothespin tag elicited means that were classified as vigorous intensity activity ( $>6 \mathrm{METs}$ ), while the others elicited moderate intensity activity (3-6 METs). Overall, activities eliciting vigorous intensity required more locomotion than those eliciting moderate intensities.
Some of the activities had previously published energy expenditure values, while others did not. Bowling (3.6 METs) was previously measured in 1 child study $(n=12 ; 11.4$ years of age), eliciting 4.9 METs. ${ }^{1,9}$ The previous study did not specify what type of bowling, but it was likely with plastic pins and plastic ball as used in the current study due to the study's location (in a laboratory). It is important for researchers to provide activity descriptions so others wishing to use or compare energy expenditure data do not have to make inferences. One key difference between studies was that our study allowed children to play in groups for all activities, which could affect effort and energy expenditure due to the wait time associated with taking turns, but may better represent how children play these games in real life.

Four other activities elicited moderate intensity. Catch (4.0 METs) was previously measured in 2 child studies $(n=51)$, in which a moderate effort elicited 2.6 METs. ${ }^{1}$ The current study had low sample size for this activity $(n=6)$, which was part of unstructured play, so the parameters (eg, duration, effort) were not as strict as they may have been in previous research. Further, the use of a Velcro catching mitt may have reduced the need for youth to chase after missed catches. Basketball (5.7 METs), specifically "shooting hoops," was included in the compendium as measured in 1 child study $(n=74)$ and elicited 7.2 METs. ${ }^{1}$ In the current study, basketball was an unstructured activity, so children were free to choose their own intensity and duration. Although children sometimes played an actual game, they often chose to shoot hoops instead. Since they could play in groups, this may have involved more standing and waiting for a turn than the previous research in which the subjects shot basketballs continuously by themselves. Further, the previous study only included adolescent girls. ${ }^{10}$ Additionally, a study by Lyden et $\mathrm{al}^{11}$ found that children (8-11 years) and adolescents (12-16 years) expended 6.6 and 7.6 METs, respectively during basketball. In the Lyden study, pace was self-selected, but children played alone, suggesting they may have been more active due to increased ball time.

Two of the moderate intensity activities were not previously measured in children. For juggling scarves, our finding of 4.1 METs was similar to the 4.0 METS listed in the adult compendium, although how the compendium MET level was determined was not specified to allow for better comparison. ${ }^{1}$ For tennis, adult data suggest that tennis on a court elicits 5.3 METs even at a light effort, 


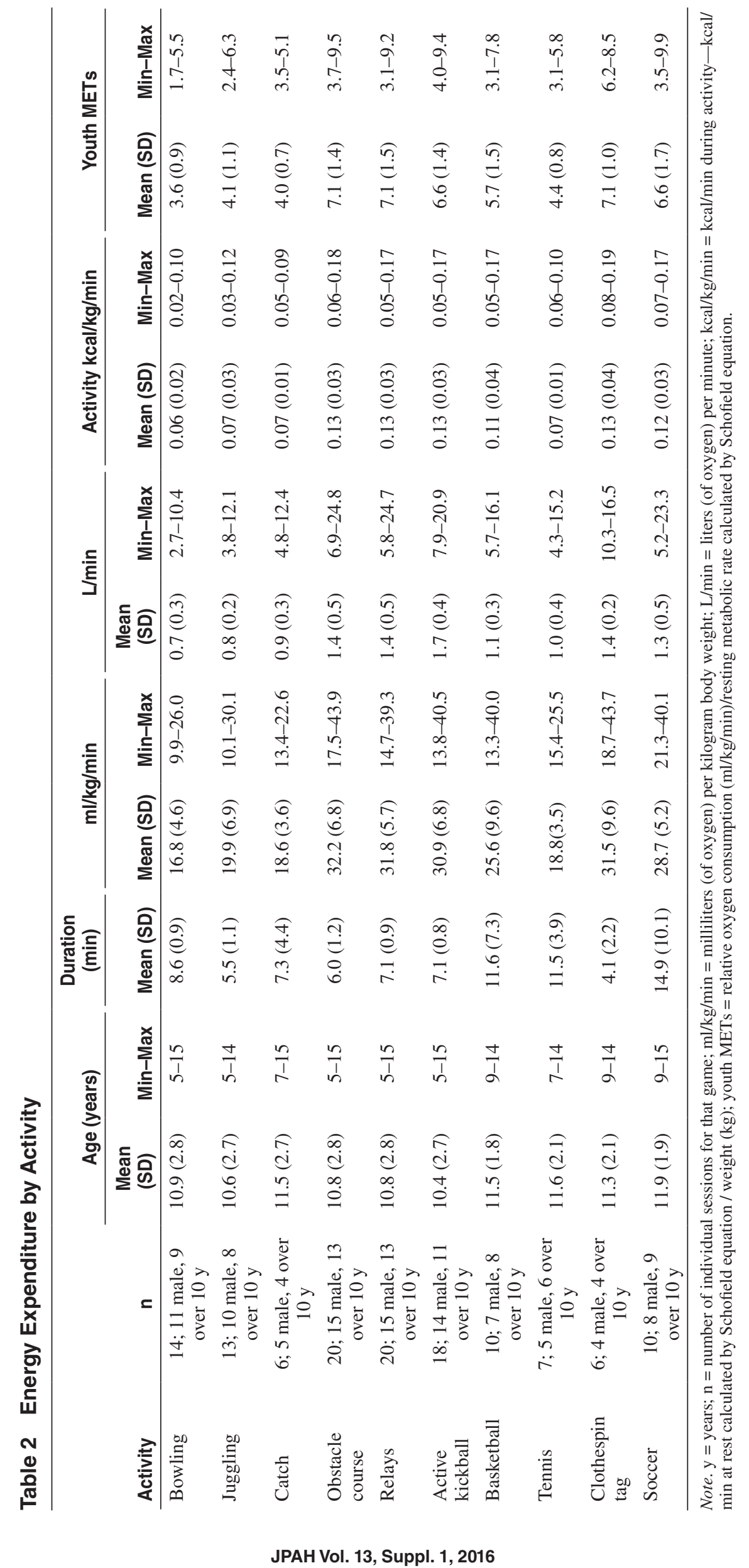


while the current study only elicited 4.4 METs. ${ }^{1}$ This was likely due to the children using plastic rackets and foam balls and playing at a self-determined distance apart, not on a standard tennis court.

Five activities elicited vigorous intensity, 3 of which had previously published values. In the youth compendium, tag was measured in 1 previous study, from 1923, and elicited 5.0 METs, lower than the 7.1 METs in the current study. ${ }^{1}$ This discrepancy is likely due to fewer children playing in a smaller space in the current study, which would require more constant movement. Further, in clothespin tag, there is no one person who is being chased; everyone is both chasing and being chased. However, a similar tag game, Dragon's Tail, was measured previously and elicited 5.8 METs compared with 7.1 METs in the current study. ${ }^{5}$ Active kickball elicited 6.6 METs, compared with the 7.0 METs as listed in the adult compendium. ${ }^{1}$ The current study importantly used active kickball, a modification of that replaces standing on a base with activities like marching or dancing. In the youth compendium, the energy cost of soccer was based on a study conducted in $1923 .{ }^{1}$ The current study observed an energy cost 6.6 METs as compared with 8.8 METs listed in the youth compendium for moderate effort soccer. The previous study was conducted almost 100 years ago using a modified Douglas bag on children in England, possibly limiting generalizability to American children in the present day. Regardless, the lower energy expenditure in our study is likely due to the smaller play space requiring less running.

Neither obstacle course nor relays were previously reported in the youth compendium. However, they are important due to their inclusion in physical education, youth sports practice, and afterschool programs. Further, they elicited vigorous activity (both 7.1 METs). Howe et al measured "Cardio Course," similar to the obstacle course, but elicited only 4.9 METs compared with 7.1 METs in the current study. ${ }^{5}$

The main limitation of this study was that the sample was predominantly male, and sample size did not allow analysis of differences in energy expenditure by sex, age, or weight status. The wide age range of subjects participating in each activity is also an important limitation because energy expenditure may decline with advancing age. ${ }^{3}$ Previous research has shown that calculation of youth METs can equalize these differences by accounting for higher resting energy expenditure of younger children. ${ }^{3}$ This study provides energy cost data on activities not previously described in the youth compendium.

In conclusion, this study provides additional data on energy cost of games commonly played by children. Future research should contribute to the compendium by measuring these activities in larger, more diverse samples, while ensuring activities are adequately described to account for differences in play environment and equipment.

\section{Acknowledgments}

The authors thank Laura Vielbig, Sharla Gillespie, Kolton Brusveen, Justine Hatcher, and Adam Smith for their help with data collection. This research was funded by the North American Society for Pediatric Exercise Medicine Student Research Award.

\section{References}

1. Ridley K, Ainsworth BE, Olds TS. Development of a compendium of energy expenditures for youth. Int J Behav Nutr Phys Act. 2008;5:45. PubMed doi:10.1186/1479-5868-5-45

2. Ridley K, Olds T. Assigning energy costs to activities in children: a review and synthesis. Med Sci Sports Exerc. 2008;40(8):1439. PubMed doi:10.1249/MSS.0b013e31817279ef

3. Harrell JS, McMurray RG, Baggett CD, Pennell ML, Pearce PF, Bangdiwala SI. Energy costs of physical activities in children and adolescents. Med Sci Sports Exerc. 2005;37(2):329-336. PubMed doi:10.1249/01.MSS.0000153115.33762.3F

4. Rowland TW. Children's Exercise Physiology. 2nd ed. Champaign, IL: Human Kinetics; 2005.

5. Howe CA, Freedson PS, Feldman HA, Osganian SK. Energy expenditure and enjoyment of common children's games in a simulated free-play environment. J Pediatr. 2010;157(6):936-942. PubMed doi:10.1016/j.jpeds.2010.06.041

6. Schofield W. Predicting basal metabolic rate, new standards and review of previous work. Hum Nutr Clin Nutr. 1985;39:5-41. PubMed

7. Pate RR, Pratt M, Blair SN, et al. Physical activity and public health: a recommendation from the Centers for Disease Control and Prevention and the American College of Sports Medicine. JAMA. 1995;273(5):402407. PubMed doi:10.1001/jama.1995.03520290054029

8. Kraemer W, Fleck S, Deschenes M. Exercise Physiology. Philadelphia, PA: Lippincott Williams \& Wilkins; 2012.

9. Eisenmann JC, Strath SJ, Shadrick D, Rigsby P, Hirsch N, Jacobson L. Validity of uniaxial accelerometry during activities of daily living in children. Eur J Appl Physiol. 2004;91(2-3):259-263. PubMed doi:10.1007/s00421-003-0983-3

10. Pfeiffer KA, Schmitz KH, McMurray RG, Treuth MS, Murray DM, Pate RR. Physical activities in adolescent girls: variability in energy expenditure. Am J Prev Med. 2006;31(4):328-331. PubMed doi:10.1016/j.amepre.2006.06.002

11. Lyden K, Keadle SK, Staudenmayer J, Freedson P, Alhassan S. Energy cost of common activities in children and adolescents. $J$ Phys Act Health. 2013;10(1):62-69. PubMed 